\title{
Fludazonium Chloride
}

National Cancer Institute

\section{Source}

National Cancer Institute. Fludazonium Chloride. NCI Thesaurus. Code C65708.

A polychlorophenyl compound used as a topical antiseptic. 